\title{
The Forgotten Antiproteinuric Properties of Diuretics
}

\author{
Hernando Trujillo ${ }^{a}$ Fernando Caravaca-Fontán ${ }^{b} \quad$ Jara Caro $^{a, b}$ \\ Enrique Morales ${ }^{a, b}, c$ Manuel Praga ${ }^{a, b, c}$
}


Hospital Universitario 12 de Octubre (imas12), Madrid, Spain; 'Department of Medicine, Universidad Complutense de Madrid, Madrid, Spain

\section{Keywords}

Diuretics · Proteinuria · Thiazides · Aldosterone

antagonists · Sodium-glucose cotransporter-2 inhibitors

\begin{abstract}
Background: Although diuretics are one of the most widely used drugs by nephrologists, their antiproteinuric properties are not generally taken into consideration. Summary: Thiazide diuretics have been shown to reduce proteinuria by $>35 \%$ in several prospective controlled studies, and these values are markedly increased when combined with a lowsalt diet. Thiazide-like diuretics (indapamide and chlorthalidone) have shown similar effectiveness. The antiproteinuric effect of mineralocorticoid receptor antagonists (spironolactone, eplerenone, and finerenone) has been clearly established through prospective and controlled studies, and treatment with finerenone reduces the risk of chronic kidney disease progression in type-2 diabetic patients. The efficacy of other diuretics such as amiloride, triamterene, acetazolamide, or loop diuretics has been less explored, but different investigations suggest that they might share the same antiproteinuric properties of other diuretics that should be evaluated through controlled studies. Although the inclusion of sodium-glucose cotransporter-2 inhibitors (SGLT2i) among diuretics is a controversial issue, their renoprotective and
\end{abstract}

cardioprotective properties, confirmed in various landmark trials, constitute a true revolution in the treatment of patients with kidney disease. Recent subanalyses of these trials have shown that the early antiproteinuric effect induced by SGLT2i predicts long-term preservation of kidney function. Key Message: Whether the early reduction in proteinuria induced by diuretics other than finerenone and SGLT2i, as summarized in this review, also translates into long-term renoprotection requires further prospective and observational studies. In any case, it is important for the clinician to be aware of the antiproteinuric properties of drugs so often used in daily clinical practice.

(c) 2021 S. Karger AG, Basel

\section{Introduction}

Chronic kidney disease (CKD) is associated with increased morbidity and mortality, especially at later stages, which results in significantly higher health expenditures [1-3]. However, despite the high burden of CKD, only few therapies have proven to be effective for slowing or

Hernando Trujillo and Fernando Caravaca-Fontán contributed equally to this article.
Correspondence to:

Manuel Praga,mpragat@ senefro.org 
halting the progression. To a large extent, this is due to the slowly progressive nature of many forms of kidney diseases that challenge the design of clinical trials with hard end points [4]. Therefore, the use of surrogate end points to predict clinically relevant events and to investigate the potential effectiveness of new therapeutic strategies has become compulsory [5].

A large body of evidence has shown that albuminuria is among the most important markers to predict the risk of disease progression and the cardiovascular complications that frequently accompany CKD [6-8]. A sustained exposure and uptake of high amounts of albumin by tubular cells exert cytotoxic effects and trigger inflammatory pathways that ultimately lead to tubulointerstitial damage [4, 9-12].

Blood pressure control and albuminuria reduction represent the cornerstone of therapy to slow CKD progression. Renin-angiotensin system (RAS) blockers - either angiotensin-converting enzyme inhibitors (ACEIs) or angiotensin II receptor blockers (ARBs) - are a mainstay of therapy for both purposes [11-16]. Several pivotal trials have demonstrated the efficacy of these agents on the progression of both diabetic and nondiabetic nephropathies, mainly related to their antialbuminuric properties [12, 14-18]. However, a substantial proportion of patients are resistant to the antiproteinuric effects of these drugs and residual albuminuria may persist in others, despite maximum tolerated doses of RAS blockade, which in the long-term translates into progression of kidney damage $[5,19,20]$.

Within the armamentarium of drugs that nephrologists use in their daily clinical practice, diuretics are among the most important drugs. Their antihypertensive effects have been demonstrated for a long time, and management of the edema caused by different proteinuric glomerular diseases or the volume overload that commonly accompanies $\mathrm{CKD}$, particularly in its later stages, usually requires the use of diuretics. However, despite this familiarity of nephrologists with diuretic therapy, few clinicians take into consideration the antiproteinuric properties that various types of diuretics have shown in studies performed in the last years. Although the number of such studies is relatively small and their design has been focused mainly on the short term, most of them have obtained concordant results, showing a numerically important proteinuria reduction. The only diuretics whose antiproteinuric and renoprotective effects have been tested in large clinical trials with hard end points have been aldosterone antagonists (spironolactone, eplerenone, and finerenone). However, other types of diuretics widely used in clinical practice, such as hydrochlorothiazide (HCT), chlorthalidone, indapamide, amiloride, or acetazolamide (AAZ) have also shown a remarkable antiproteinuric effect, at least in the short term. Noteworthy, most (if not all) studies that have proven that various diuretics decrease proteinuria have been designed on subjects who were already taking RAS blockers or on a lowsalt diet. Thus, diuretics should be contemplated as a combination therapy for kidney protection. Given the increasingly established relationship between reduction in albuminuria and long-term renoprotection, the possible preventive effect these diuretics may have on the progression of CKD is a matter of utmost importance that should be explored by means of larger, prospective, and well-designed trials. In this review, we aimed to update the current knowledge and scientific studies addressing the antiproteinuric properties of diverse diuretics.

\section{Thiazide Diuretics}

Different clinical trials have shown that thiazide diuretics - alone or in combination with $\beta$-blockers, RAS blockade, and calcium antagonists - reduce morbidity and mortality in hypertensive individuals through a reduction in the incidence of congestive heart failure (HF) and stroke $[21,22]$. The mechanism of action of thiazide diuretics is primarily mediated through inhibition of the sodium chloride cotransporter in the distal convoluted tubule, although other less prominent effects have also been described along the proximal and the cortical collecting tubule $[23,24]$. Nonetheless, the natriuretic effect of thiazide diuretics is smaller than that of loop diuretics, which in general makes them less appropriate for edematous states. High-salt diet may elicit a change on renal hemodynamics toward hyperfiltration, especially in sodium-sensitive patients and those with a high body mass index [25-27]. This may be due to an inappropriate activity of the RAS [25].

Low-sodium diet enhances the antiproteinuric effects of RAS blockade [28, 29]. Indeed, the renoprotective and cardioprotective effects of RAS have been demonstrated to be greater during a concomitant low-sodium diet [30, 31]. However, in clinical settings and particularly with certain patients, this may be a difficult goal to achieve. The addition of low dose HCT has been shown to restore the antiproteinuric and blood pressure-lowering efficacy of RAS blockade, blunted by a high-salt diet [32]. Several studies have extensively analyzed the effect of sodium restriction and diuretic treatment on proteinuria reduction 
in both nondiabetic and diabetic patients [33-38], and the most relevant evidence is summarized in the following lines:

Vogt et al. [35] examined in detail the separate and combined effects of a low-sodium diet and HCT on proteinuria and blood pressure in 34 nondiabetic patients. The authors found that both sodium restriction $\left(1.2 \mathrm{~g} \mathrm{Na}^{+}\right.$ per day) and diuretic therapy (25-mg HCT) were equally effective in reducing proteinuria and blood pressure when added to RAS blockade ( 55 and 56\%, respectively), although the largest effect on proteinuria was obtained during their combination (proteinuria reduction of $70 \%$ from baseline) [35]. Interestingly, sodium restriction and HCT led to similar decrease in kidney function during treatment with RAS blockade, and this decrease did not account for the decrease in proteinuria, suggesting that further reduction in proteinuria may be obtained by further sodium reduction [35].

Kwakernaak et al. [37] evaluated the independent and added effects of sodium restriction and HCT (in combination with RAS blockade) on residual albuminuria in a crossover randomized trial that included 45 patients with diabetes mellitus. Patients were given $50 \mathrm{mg}$ HCT or placebo during 4 treatment periods of 6 weeks, and the latter were combined with sodium restriction $\left(1.2 \mathrm{~g} \mathrm{Na}^{+}\right.$per day) or a regular sodium diet. Both sodium restriction and HCT significantly reduced albuminuria irrespective of the sequence ( $44 \mathrm{vs.} 39 \%$ albuminuria reduction from baseline), albeit this reduction was greatest when combined (57\% albuminuria decrease) [37]. However, this combination was associated with a slight and reversible reduction in kidney function (Tables 1-4).

Another randomized trial assessed the potential benefit of HCT (12.5 mg/day) on proteinuria reduction among 102 patients with CKD under treatment with losartan (50 mg/day) [38]. After 12 months of treatment, a significantly greater degree of urinary protein-to-creatinine ratio reduction was observed in the group of patients who received HCT (mean urinary protein-to-creatinine ratio decline $-0.55 \mathrm{~g} / \mathrm{g}$ ), without a significant difference in blood pressure, suggesting that the potential underlying mechanism could be independent of blood pressure reduction [38]. Similar results were reported in another small study that examined the renoprotective effects of thiazides combined with loop diuretics in patients with diabetic nephropathy, an estimated glomerular filtration rate $(\mathrm{eGFR})<30 \mathrm{~mL} / \mathrm{min} / 1.73 \mathrm{~m}^{2}$, and severe edema [39].

The exact underlying antiproteinuric mechanism of thiazides has not yet been elucidated, although it has been suggested that they may induce a reduction in intraglomerular pressure through depletion of intravascular volume $[35,40,41]$. As a result, both body weight and total body volume decrease, and serum creatinine and uric acid may increase [40,41]. The reported improvement in eGFR after discontinuing thiazide treatment and during the long-term follow-up is consistent with this proposed mechanism [42]. Thus, diuretics may induce immediate acute kidney function impairment, especially when combined with RAS blockade, but in the long-term, this could predict better kidney outcomes, possibly as a result of an improvement of glomerular hypertension $[37,42]$.

To summarize, all the aforementioned studies support the use of thiazides, especially for those patients who are unable to comply with a low-sodium diet, or as an add-on therapy in cases with significant residual albuminuria, despite maximum tolerated doses of RAS blockade, or a tendency towards hyperkalemia $[32,37,40]$. Nonetheless, this decision should be individualized according to the patient profile, considering the metabolic side effects of these agents [43], and also other potential long-term effects of thiazide exposure [44].

\section{Thiazide-Like Diuretics}

The antiproteinuric effects of thiazide-like diuretics such as chlorthalidone and indapamide - have also been studied. A 12-week pilot study tested the effects of chlorthalidone in 12 patients with moderate to advanced CKD and found a 40-45\% albuminuria reduction [41]. However, patients experienced a concomitant rise in serum creatinine at week 8 attributed to volume depletion, followed by a gradual improvement and return to baseline at 12 weeks [41]. This transient rise in serum creatinine was paralleled by a decrease in total body weight and an increase in renin and aldosterone levels [41].

Similar results have been reported in the kidney transplant population with an observed $30 \%$ proteinuria reduction and decrease of peripheral edema, albeit with a transient worsening in kidney function, which could otherwise complicate the assessment of a possible rejection [42]. Indapamide has also been shown to reduce albuminuria alone or in combination with RAS blockade in diabetic patients with persistent albuminuria [45-48]. 


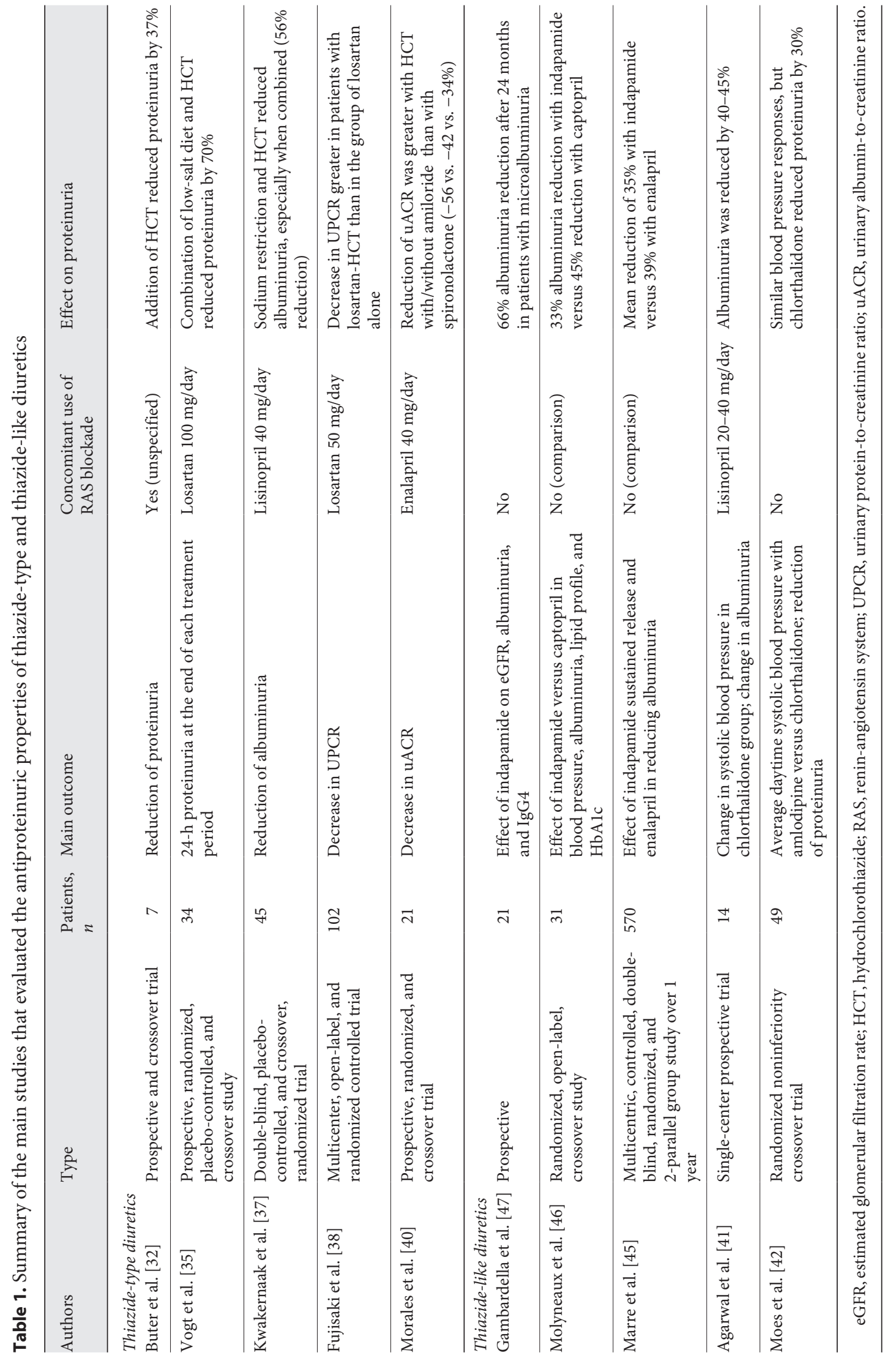




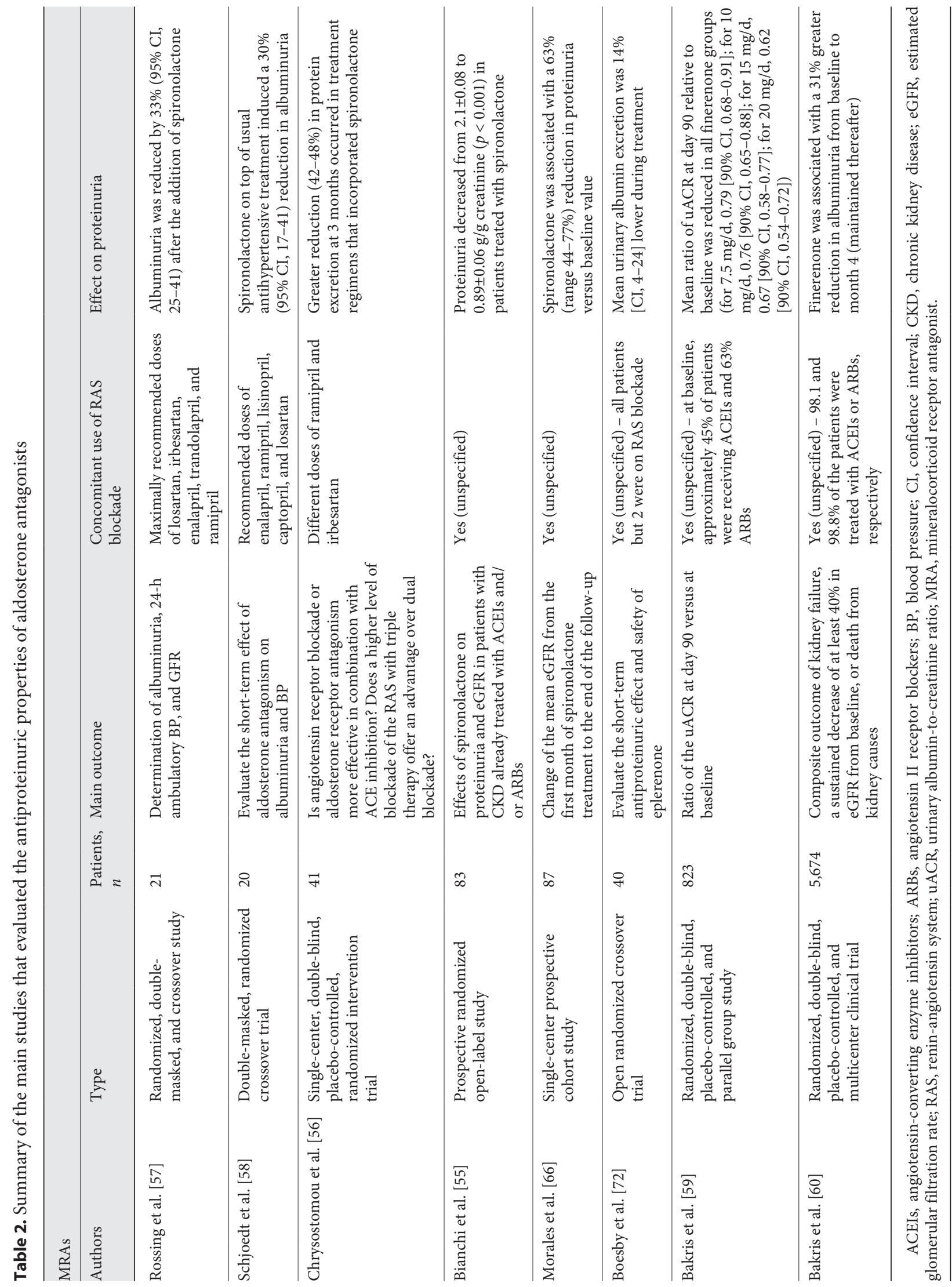




\section{Loop Diuretics}

Loop diuretics are widely used in clinical practice for the treatment of systemic edema. However, only few studies have analyzed the potential antiproteinuric properties of loop diuretics when combined with standard RAS blockade. Esnault et al. $[49,50]$ found that a cautious increase in furosemide dosage in addition to combined half doses of ACEIs and ARBs better-decreased proteinuria than uptitration to the full dose of ACEIs and ARBs. This antiproteinuric effect could be partially explained by the concomitant eGFR decline due to volume depletion, suggesting the contribution of hemodynamic modifications in this effect $[49,50]$. Nonetheless, it should be noted that increased furosemide dosage had also a profound effect over systolic blood pressure, advocating the possibility that the influence on proteinuria may have been a consequence of the hypotensive effect. Conversely, an experimental study failed to show added benefits of the combination of losartan plus furosemide - as compared to losartan plus HCT - in terms of blood pressure control, reduction of albuminuria and mortality in a 5/6 nephrectomy rat model [51].

Thus, it is not yet clear whether the antiproteinuric effect is achieved when an effective decrease in extracellular volume is achieved, leading to transient kidney function impairment. One must consider that there is no sharp evidence that thiazide or loop diuretics per se are capable of lowering proteinuria, rather, its mechanism of action in this context is probably related to the potentiation of the effect of RAS blockade by making intraglomerular pressure more RAS-dependent. The latter also applies to the effect of low-salt diet.

\section{Aldosterone Antagonists}

The physiologic functions of aldosterone on kidney sodium reabsorption, potassium handling, extracellular volume, and blood pressure homeostasis, are widely acknowledged. However, aldosterone also represents a major player for the development of vascular injury resulting in kidney fibrosis, and several animal models have shown that blocking aldosterone mitigates vascular damage and reduces proteinuria [52-54]. The myriad of beneficial effects of aldosterone blockade on kidney outcomes has been further established in humans in numerous randomized controlled trials [55-60].

Although one would expect that angiotensin blockade would ultimately suppress aldosterone, it has been observed that a subset of patients exhibits aldosterone es-

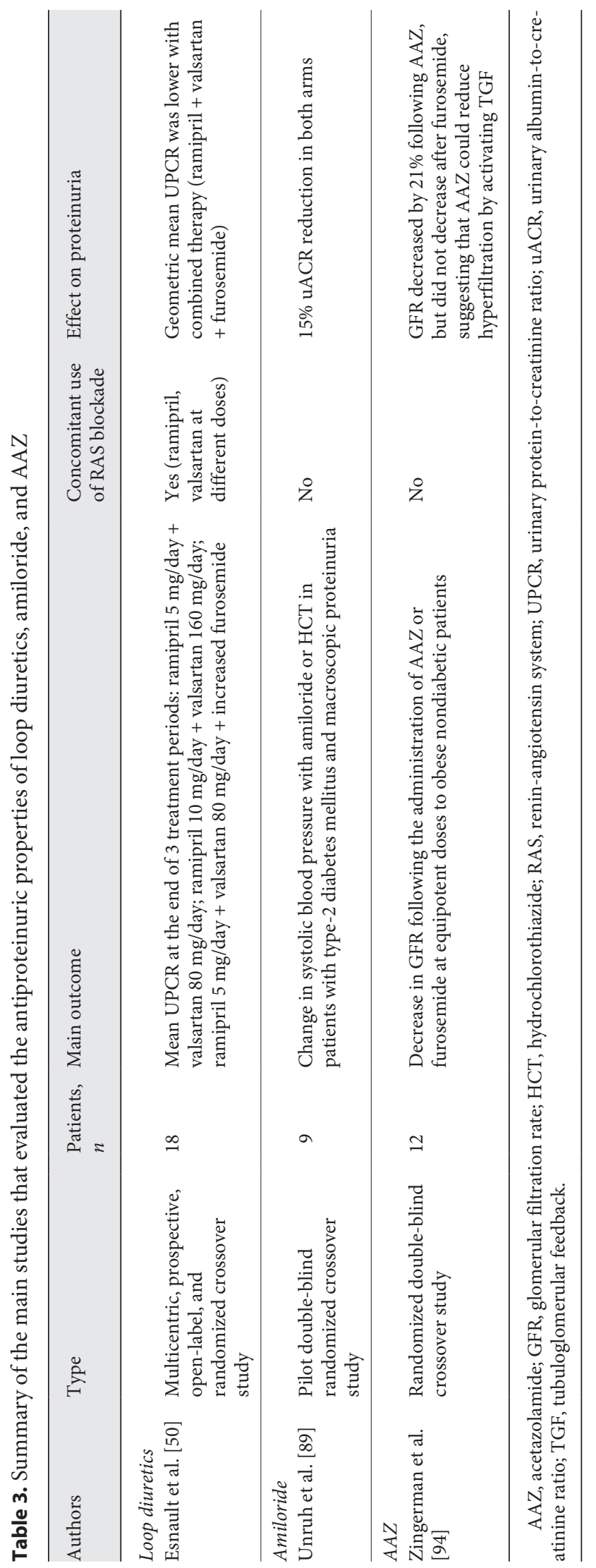

Trujillo/Caravaca-Fontán/Caro/Morales/ Praga 


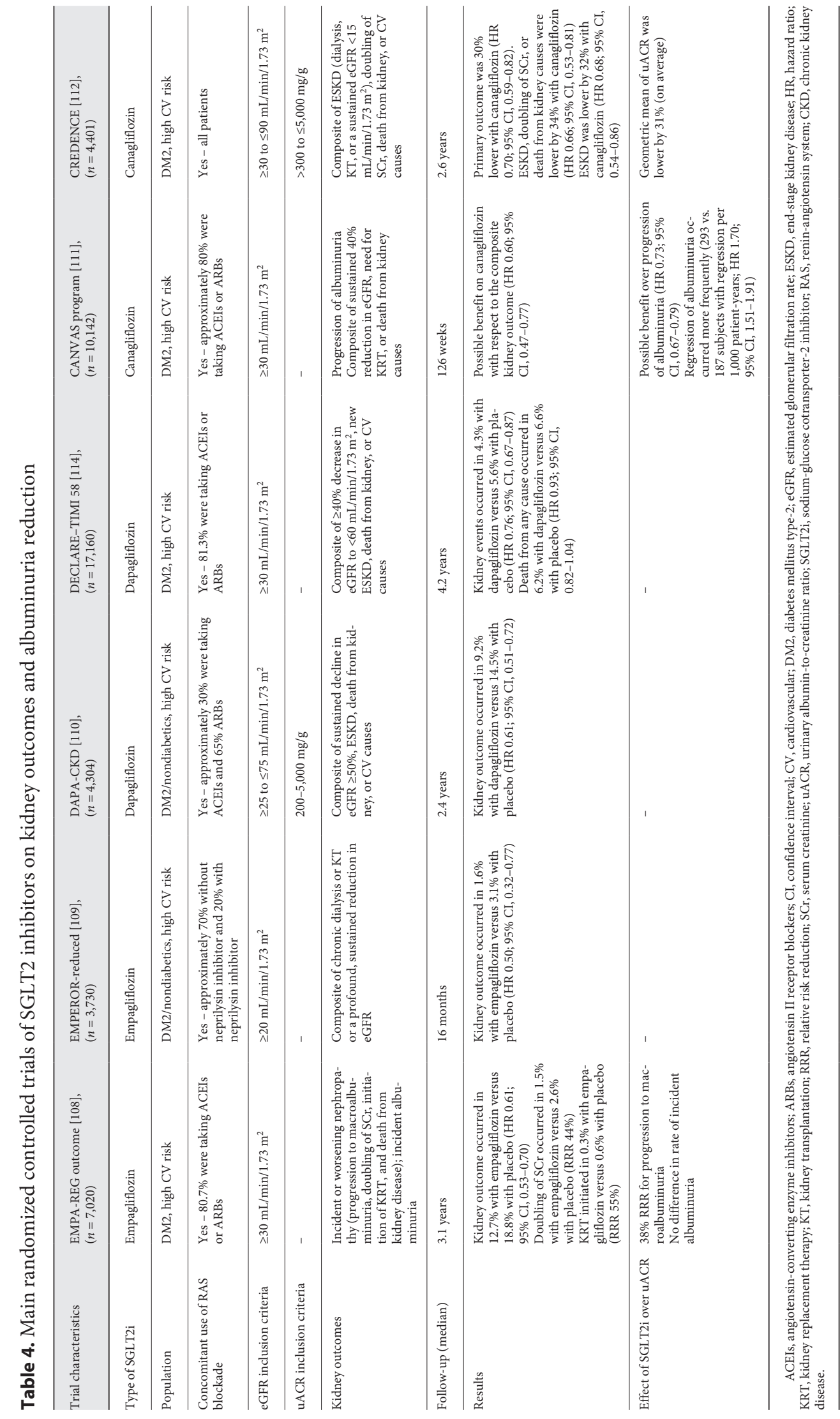


cape over time, with the resultant attenuation of the effect of ACEIs and ARBs treatment [61-63]. Thus, aldosterone blockade with mineralocorticoid receptor antagonists (MRAs) appears as a potential target for mitigating progression of CKD and might offer additive benefits to other antiproteinuric agents. In fact, the strongest evidence regarding the positive effect over proteinuria comes from studies where MRAs were introduced to patients who were already on ACEIs and/or ARBs treatment. Hence, when considering the use of MRAs with the aim of reducing proteinuria, these agents should ideally be used as an adjuvant therapy in subjects with maximized doses of ACEIs/ARBs $[55,56,60]$. Nonetheless, MRAs have a double effect: natriuresis and RAS inhibition. Therefore, decreased proteinuria may be achieved through the RASinhibitory effect, which in turn may be stimulated by the natriuretic effect, increasing RAS dependency. Considering this, MRAs might reduce proteinuria without concomitant RAS blockade and ultimately have an impact on kidney disease progression. Currently available MRAs include spironolactone, eplerenone, and finerenone.

\section{Spironolactone}

Spironolactone is a nonselective MRA that is metabolized in the liver to its active metabolite canrenone $[64,65]$. In addition to the dreaded hyperkalemia, the structural similarity of spironolactone with progesterone accounts for the potential appearance of breast tenderness and gynecomastia [64]. Different studies have shown that the use of spironolactone on top of ACEIs and/or ARBs induces a proteinuria reduction of approximately 30-40\% [55-57], and no additional benefit has been observed from triple blockade (ACEIs + ARBs + spironolactone) over dual blockade (ACEIs + spironolactone) [56]. Of note, albeit eGFR initially descends after spironolactone initiation, the monthly rate of eGFR decline is lower in treated patients in the long run $[55,58,66]$. In fact, MRAs in addition to ACEIs and/or ARBs are associated with a change in eGFR of $-2.38 \mathrm{~mL} /$ $\mathrm{min} / 1.73 \mathrm{~m}^{2}$ [65]. Interestingly, it has been observed that baseline aldosterone levels might predict the degree of reduction in proteinuria and the future rate of change in eGFR with MRAs therapy $[55,67]$. On the other hand, the most recent evidence of MRAs over CKD progression comes from studies aimed at diabetic nephropathy. The renoprotective effects of spironolactone have been demonstrated in both type- 2 and type- 1 diabetic patients [56, 57, 67-70]. Of interest, it has been reported that albuminuria reduction is not necessarily correlated with the improvement in blood pressure control observed with aldosterone blockade, in both diabetic and nondiabetic patients $[57,71,72]$.

\section{Eplerenone and Finerenone}

Eplerenone is a selective MRA that presents less affinity for progesterone receptors, and therefore lacks endocrinologic-related adverse effects [64], while finerenone is a novel selective nonsteroidal MRA that has demonstrated greater affinity than eplerenone and lower risk of hyperkalemia $[59,65]$. In addition, finerenone has a distinct mechanism of action which translates into less proinflammatory and pro-fibrotic gene expression, with marked anti-fibrotic efficacy observed in preclinical models [73].

Until recently, the evidence on the reduction of proteinuria with eplerenone and finerenone was limited [67, $69,71,72,74,75$ ]. In 2015, Bakris et al. [59] published the results of a large multicenter randomized controlled study that compared the antiproteinuric effect of finerenone versus matching placebo in subjects with type- 2 diabetes mellitus with high or very high albuminuria who were already under ACEIs/ARBs treatment. Although the follow-up time was short, the finerenone arm presented a significant improvement in the urinary albumin-to-creatinine ratio (uACR) as compared to the control group [59]. Subsequently, the eagerly awaited results from the FIDELIO-DKD study have been recently brought to light [60]. In this large double-blind trial, the addition of finerenone to RAS blockade in type-2 diabetic patients resulted in lower risks of CKD progression and cardiovascular events than placebo after a median follow-up of 2.6 years. The primary composite outcome included kidney failure, a sustained decrease of at least $40 \%$ in eGFR from baseline, or death from kidney causes, which occurred in $17.8 \%$ of patients in the finerenone group versus $21.1 \%$ in the placebo group (hazard ratio $0.82 ; p=0.001$ ). Finerenone was associated with a $31 \%$ greater reduction in albuminuria from baseline to month 4 , which was maintained thereafter. More patients on the finerenone arm exhibited hyperkalemia leading to drug discontinuation (2.3 and $0.9 \%$, respectively). Of interest, despite multiple studies demonstrating positive results in patients with CKD, a recent Cochrane Database Systematic Review which included studies up to January 2020 reported that the effects of MRAs when added to ACEI or ARB (or both) on the risks of death, major cardiovascular events, and kidney failure in people with proteinuric CKD are still uncertain [76]. One must consider that the latter conclusions were based on evidence of very low to low certainty due to methodological limitations in the included studies and serious imprecision in estimated treatment effects. The majority of comprised studies enrolled a limited number of patients and were designed to observe dif- 
ferences in surrogate end points (proteinuria and blood pressure) rather than patient-focused outcomes (kidney failure, death, and major cardiovascular events).

\section{Additional Data on MRAs}

Beyond its antiproteinuric and renoprotective effects, MRAs decrease morbidity and mortality in patients with $\mathrm{HF}$ and reduced ejection fraction. A recent systematic review found that these positive effects are also observed in CKD patients with HF and an eGFR between 30 and 60 $\mathrm{mL} / \mathrm{min} / 1.73 \mathrm{~m}^{2}$. The authors reported that MRAs therapy reduces cardiovascular events, all-cause mortality, and HF hospitalization, despite higher risks of hyperkalemia and drug discontinuation in this subset of patients [77]. In contrast, a small randomized study found no effect of spironolactone on the cardiovascular parameters of maintenance hemodialysis patients [78]. On the other hand, MRAs have demonstrated to be effective for the management of resistant and refractory hypertension, and animal models have suggested a positive endovascular effect of finerenone through rebuilding vascular integrity and preventing development of vascular remodeling [79-82]. This is relevant since difficult-to-control hypertension and peripheral vascular disease are frequently encountered in the CKD population. Of interest, other novel nonsteroidal MRAs, such as apararenone and esaxerenone are currently being tested in several clinical trials for other disorders, including nonalcoholic steatohepatitis and primary aldosteronism [83].

\section{Amiloride and Triamterene}

Amiloride and triamterene are other types of potassium-sparing diuretics that, unlike aldosterone antagonists, do not affect the mineralocorticoid receptor. Experimental studies have described an antiproteinuric effect of amiloride, attributed to the inhibition of urokinase-type plasminogen activator receptor expression in kidney podocytes [84, 85] (a molecule associated with cell motility highly expressed in podocytes and implicated in CKD progression ) [86]. Additionally, it has been suggested that amiloride could further decrease proteinuria through an inhibition of the epithelial sodium channel on the distal nephron $[87,88]$. One study reported the antiproteinuric effectiveness of amiloride as an adjuvant therapy in a patient with Fabry disease [87].

Unruh et al. [89] conducted a randomized doubleblinded crossover study comparing the effects of the administration of amiloride or HCT to 9 diabetic patients with proteinuria. Although no significant differences were observed in the primary outcome (change in systolic blood pressure) at the end of the study, the authors observed an almost 15\% uACR reduction in both arms [89]. Finally, the preliminary results from an ongoing trial (NCT02522650), testing the effects of amiloride and triamterene on 12 proteinuric patients of different etiologies, reported a proteinuria reduction by $25 \%$ with the former and by $33.7 \%$ with the latter. Nevertheless, the risk of hyperkalemia remains the major concern associated with these drugs.

\section{Acetazolamide}

AAZ is a carbonic anhydrase inhibitor whose main indications are glaucoma and idiopathic intracranial hypertension [90]. The inhibition of carbonic anhydrase in the proximal tubule leads to bicarbonate, sodium, and chloride loss. In fact, it has been suggested that AAZ shares important similarities with sodium-glucose cotransporter-2 inhibitors (SGLT2i) as both act in the proximal tubule and suppress the sodium-hydrogen exchanger leading to natriuresis and a tendency towards metabolic acidosis (with normal anion gap in the case of AAZ and high anion gap with SGLT2i), which ultimately result in RAS inhibition and hyperfiltration reduction [91].

AAZ has long been used to prevent or attenuate acute mountain sickness [92]. Indeed, acute mountain sickness has been associated with the development of transient proteinuria, possibly due to renal hypoxia, which ultimately causes increased glomerular permeability, reduced tubular reabsorption, or both [93]. The treatment with AAZ has been shown to reduce proteinuria in this context $[92,93]$.

The effect of AAZ has also been evaluated on obesityinduced hyperfiltration. A randomized double-blinded crossover trial analyzed the effects of AAZ or furosemide at equipotent doses on glomerular hyperfiltration in 12 obese nondiabetic subjects [94]. GFR decreased by $21 \%$ following AAZ but did not decrease after furosemide, suggesting that AAZ could reduce hyperfiltration by activating tubuloglomerular feedback (TGF) [94].

\section{Comparative Studies of the Antiproteinuric Effect of Different Diuretics}

Our group was the first to perform a head-to-head comparison of the antialbuminuric effect of 3 different types of diuretics in a prospective randomized crossover study [40]. 
Twenty-one patients with CKD stages 1-3, baseline uACR $>300 \mathrm{mg} / \mathrm{g}$, and treatment with stable doses of RAS blockade during the last 3 months (before inclusion) were randomized to one of the following diuretic treatments: spironolactone $25 \mathrm{mg} /$ day, HCT $50 \mathrm{mg} /$ day, or HCT plus amiloride. Patients received each drug over a 4-week period, separated by washout periods of the same length. The results of this study revealed a significant albuminuria reduction with the 3 types of diuretics. Yet, the most novel finding was that patients treated with HCT achieved a median reduction of albuminuria of $-42 \%$. Moreover, when amiloride was combined with $\mathrm{HCT}$, the reduction was much more pronounced, reaching a median of $-56 \%$ from baseline (as compared to $-34 \%$ albuminuria reduction with spironolactone alone). In addition, eGFR, blood pressure, and body weight decreased with the 3 therapeutic regimens, and a significant correlation was found between albuminuria reduction, eGFR, and blood pressure changes [40].

\section{SGLT2is: Can They Be Considered as Diuretics?}

The renoprotective mechanisms of SGLT2is, the new major players in diabetic nephropathy, seem to be more complex than initially thought. Inhibition of SGLT2 in the proximal convoluted tubule prevents glucose and sodium reabsorption. Likewise, SGLT2i also inhibits the sodiumproton exchanger, further increasing the delivery of sodium to the loop of Henle, which results in activation of TGF feedback response with consequent attenuation of glomerular hyperfiltration $[95,96]$. Interestingly, preliminary studies pointed to a similar effect (reduction in intraglomerular capillary hydraulic pressure) with the use of AAZ [97]. Afar from the direct consequences over TGF and glycemic control, SGLT2i acts as osmotic diuretics, leading to a decrease in blood pressure and weight loss [98]. In a post hoc analysis of 2 randomized controlled trials, the use of dapagliflozin demonstrated osmotic and natriuretic diuretic effects in patients with type-2 diabetes and kidney involvement [99]. In addition, it was also observed that prolonged SGLT2i resulted in activation of compensatory mechanisms to reestablish extracellular volume homeostasis. Another remarkable observation is that the natriuretic effect of SGLT2i seems to be weaker than conventional diuretics since smaller increases in renin and aldosterone have been systematically reported [99-102]. As elegantly described by Eickhoff et al. [99], the latter observations suggest that osmotic diuresis seems to be the main factor involved in the diuretic effect of SGLT2i. It is important to consider that the diuretic and natriuret- ic effects are restricted to subjects with an eGFR $>45 \mathrm{~mL} /$ $\min$ per $1.73 \mathrm{~m}^{2}$. On the other hand, SGLT2i has also been associated to reduction of oxidative stress and mitigation of kidney hypoxia [103-105]. The numerous mechanisms involved in the cardiorenal protection of SGLT2i have been recently described in detail elsewhere [106].

SGLT2is have demonstrated to reduce the risk of progression of kidney disease (worsening of kidney function, end-stage kidney disease, and kidney death) by $45 \%$, regardless of cardiovascular disease status. The extent of benefit seems to be more pronounced in those with less severe kidney disease at baseline. On the contrary, the impact on cardiovascular outcomes appears to be greater in those with worse baseline eGFR [107]. As today, numerous randomized controlled trials and subanalysis involving different SGLT2is (empagliflozin, canagliflozin, and dapagliflozin) have systematically demonstrated a sharp renoprotective and cardioprotective effect, even in patients without diabetes and in those with advanced CKD [108-114]. Nonetheless, in spite of all the evidence favoring the use of SGLT2i in proteinuric kidney diseases (particularly in diabetic patients), the possible association between renoprotection and the antiproteinuric effect of these agents has not yet been elucidated. A recent study based on simulation analyses showed that even small albuminuria-lowering effects of dapagliflozin significantly reduced the estimated kidney risk [115]. Additionally, a post hoc analysis from the CREDENCE trial found that canagliflozin significantly increased the likelihood of achieving an albuminuria reduction at week 26, and each 30\% decrease in uACR was independently associated with a lower risk for the primary kidney outcome and major adverse cardiovascular events [116]. On the contrary, the DIAMOND trial found that a 6-week treatment with dapagliflozin did not affect proteinuria but did induce an acute and reversible decline in measured GFR and a reduction in body weight, suggesting that clinical kidney outcomes may be driven by nonproteinuric pathways [117]. Of note, although SGLT2i may potentiate the effect of concomitant RAS blockade, these agents are capable of lowering albuminuria irrespective of the presence of RAS blockers. Hence, these drugs can be given along with the aim of reducing proteinuria.

\section{Changes in Albuminuria as a Surrogate End Point for Progression of Kidney Disease}

Several studies and meta-analysis published in recent years suggest that a treatment-induced reduction in albuminuria, regardless of the type of therapeutic interven- 
tion, translates into a long-term renoprotective effect [ 7 , $8,118-120]$. In fact, a meta-analysis that included almost 30,000 patients strongly support that lowering albuminuria represents a surrogate end point for the progression of CKD, especially in subjects with high baseline albuminuria [7]. Conversely, worsening proteinuria has never been associated to an improved outcome [121]. Nonetheless, other investigations propose that it is still uncertain whether aiming at proteinuria reduces risk of patient-focused outcomes such as kidney failure and death of any cause [76].

Since early preclinical studies, it has been observed that increased glomerular filtration of proteins accelerates the progressive loss of nephrons that ensues in CKD [11]. Experimental models have shown that accumulation of filtered proteins in proximal tubular cells causes basement membrane disruption, followed by an inflammatory reaction, development of interstitial damage, and glomerular sclerosis [11, 122]. Molecules that attract macrophages and $\mathrm{T}$ cells, such as monocyte chemoattractant protein-1 and RANTES, were overexpressed in proximal tubular cells that were challenged with plasma proteins $[121,123,124]$. Also, proteinuria enhanced endothelin-1 production, activation of transcriptional NF$\kappa \mathrm{B}$, and upregulation of pro-fibrogenic factors, such as TGF- $B$ [124-127]. On the other hand, protein overload has been suggested as a potential direct stimulus for the upregulation of the complement factor $\mathrm{C} 3$ at the proximal tubule [128]. Therefore, based on the latter observations, proteinuria appears as a paramount agent in the pathophysiology of the progression of proteinuric kidney diseases. However, it is still unanswered which proteins play a predominant role as activators of tubular cells.

Albuminuria has been on the spotlight for many years, but in recent times, its importance has been highlighted by the results of the latest clinical trials based on SGLT2i and finerenone therapy. It is worth noting that reduction of uACR has been observed early after treatment onset and that the short-term reduction in albuminuria observed with SGLT2i has been associated with a decreased risk of long-term cardiovascular and kidney outcomes $[116,129]$.

This concept, also investigated in IgA nephropathy [120], has implications of enormous importance for clinical practice, since an early and strong antialbuminuric response to a particular therapeutic measure, as well as its maintenance over time, might be crucial to ensure longterm renoprotection. On the contrary, increased doses or combinations of antialbuminuric drugs ought to be con-

Antiproteinuric Properties of Diuretics sidered in those patients with a poor antialbuminuric response. The design of clinical trials to investigate the possible renoprotective efficacy of a drug would change drastically if the decrease in albuminuria is accepted as a surrogate end point for end-stage kidney disease [130, 131]. Considering the characteristic slow progression of most proteinuric kidney diseases, such a conceptual change would boost the performance of trials with a simpler, cheaper, and faster design. Obviously, such a decisive change needs an in-depth discussion by the nephrology community and further analysis. Moreover, determining the percentage of albuminuria reduction that ensures effective long-term renoprotection, as well as the albuminuria thresholds above which such renoprotective effect is weakened, or whether these thresholds are different depending on the type of kidney disease, requires further studies.

\section{Conclusions and Future Research}

In the present work, we have summarized the mechanisms of action and beneficial effects of diverse diuretics over proteinuria, and we have conducted an in-depth update of the most recent research in the field. Classic diuretics have been used for a long time in the clinical setting; however, the antiproteinuric effect of these agents remains largely unknown, even by the nephrology community. Landmark studies have unequivocally demonstrated the renoprotective effect of finerenone and different SGLT2is in addition to the standard of care (RAS blockade), and recent subanalyses of these studies showed that the early antialbuminuric effect induced by these drugs predicts long-term preservation of kidney function. Whether the premise that a reduction in albuminuria is a valid surrogate marker for long-term renoprotection can be transferred to other diuretics (spironolactone, eplerenone, thiazides and thiazide-like diuretics, amiloride, indapamide, and AAZ) whose antiproteinuric properties have been summarized in this review requires more prospective and observational studies. It is essential to keep in mind that studies that have evaluated the antiproteinuric effect of different diuretics have been performed under circumstances of RAS blockade or low-salt diet; therefore, diuretics should be considered as very important agents in combination therapy. Also, it cannot be excluded that the effect on proteinuria represents a consequence of the influence of diuretics over blood pressure, although the direct effect of lowering blood pressure as a renoprotective mechanism is still controversial. In 
any case, considering the crucial value of the amount of albuminuria for the progression of proteinuric nephropathies, it is important for the clinician to be aware of the antiproteinuric properties of drugs so frequently used in daily clinical practice.

\section{Conflict of Interest Statement}

There are no conflicts of interest to declare.

\section{Funding Sources}

This study was supported by Red de Investigación Renal (RedInRen;RD12/0021/0029) and PI 16/01685/FEDER from ISCIII, both to Manuel Praga.

\section{Author Contributions}

Conception: M.P.; library search and identification of articles: H.T., F.C.F., J.C., E.M., and M.P.; summarization of articles: H.T., F.C.F., and M.P.; manuscript writing and drafting: H.T., F.C.F., and M.P.; the final approval of the manuscript: all authors.

\section{References}

1 Eckardt K-U, Coresh J, Devuyst O, Johnson RJ, Köttgen A, Levey AS, et al. Evolving importance of kidney disease: from subspecialty to global health burden. Lancet. 2013 Jul; 382(9887): 158-69.

2 Hill NR, Fatoba ST, Oke JL, Hirst JA, O'Callaghan CA, Lasserson DS, et al. Global prevalence of chronic kidney disease: a systematic review and meta-analysis. PLoS One. 2016;11(7): 0158765

3 Bikbov B, Purcell CA, Levey AS, Smith M, Abdoli A, Abebe M, et al. Global, regional, and national burden of chronic kidney disease, 1990-2017: a systematic analysis for the Global Burden of Disease Study 2017. Lancet. 2020;395(10225):709-33.

4 Cravedi P, Remuzzi G. Pathophysiology of proteinuria and its value as an outcome measure in chronic kidney disease. Br J Clin Pharmacol. 2013 Feb;76(4):516-23.

5 Stevens LA, Greene T, Levey AS. Surrogate end points for clinical trials of kidney disease progression. Clin J Am Soc Nephrol. 2006 Jul; $1(4): 874-84$.

6 Coresh J, Heerspink HJL, Sang Y, Matsushita $\mathrm{K}$, Arnlov J, Astor BC, et al. Change in albuminuria and subsequent risk of end-stage kidney disease: an individual participant-level consortium meta-analysis of observational studies. Lancet Diabetes Endocrinol. 2019;7(2):115-27.

7 Heerspink HJL, Greene T, Tighiouart H, Gansevoort RT, Coresh J, Simon AL, et al. Change in albuminuria as a surrogate endpoint for progression of kidney disease: a meta-analysis of treatment effects in randomised clinical trials. Lancet Diabetes Endocrinol. 2019;7(2):128-39.

8 Levey AS, Gansevoort RT, Coresh J, Inker LA, Heerspink HL, Grams ME, et al. Change in albuminuria and GFR as end points for clinical trials in early stages of CKD: a Scientific Workshop Sponsored by the national kidney foundation in collaboration with the US food and drug administration and European medicines agency. Am J Kidney Dis. 2020;75(1):84-104.

9 Birn H, Christensen EI. Renal albumin absorption in physiology and pathology. Kidney Int. 2006 Feb;69(3):440-9.
10 Gekle M. Renal tubule albumin transport. Annu Rev Physiol. 2005 Mar;67(1):573-94.

11 Remuzzi G, Bertani T. Pathophysiology of progressive nephropathies. N Engl J Med. 1998 Nov;339(20):1448-56.

12 de Zeeuw D, Remuzzi G, Parving H-H, Keane WF, Zhang Z, Shahinfar S, et al. Albuminuria, a therapeutic target for cardiovascular protection in type 2 diabetic patients with nephropathy. Circulation. 2004 Aug;110(8):921-7.

13 El-Atat FA, Stas SN, McFarlane SI, Sowers JR. The relationship between hyperinsulinemia, hypertension and progressive renal disease. J Am Soc Nephrol. 2004 Nov;15(11):2816-27.

14 Holtkamp FA, de Zeeuw D, de Graeff PA, Laverman GD, Berl T, Remuzzi G, et al. Albuminuria and blood pressure, independent targets for cardioprotective therapy in patients with diabetes and nephropathy: a post hoc analysis of the combined RENAAL and IDNT trials. Eur Heart J. 2011 Jun;32(12):1493-9.

15 Eijkelkamp WBA, Zhang Z, Remuzzi G, Parving $\mathrm{H}-\mathrm{H}$, Cooper ME, Keane WF, et al. Albuminuria is a target for renoprotective therapy independent from blood pressure in patients with type 2 diabetic nephropathy: post hoc analysis from the reduction of endpoints in NIDDM with the angiotensin II antagonist Losartan (RENAAL) trial. J Am Soc Nephrol. 2007 May; 18(5):1540-6.

16 Remuzzi G, Ruggenenti P, Perna A, Dimitrov $\mathrm{BD}$, de Zeeuw D, Hille DA, et al. Continuum of renoprotection with losartan at all stages of type 2 diabetic nephropathy: a post hoc analysis of the RENAAL trial results. J Am Soc Nephrol. 2004 Dec;15(12):3117-25.

17 Parving HH, Lehnert H, Bröchner-Mortensen J, Gomis R, Andersen S, Arner P, et al. The effect of irbesartan on the development of diabetic nephropathy in patients with type 2 diabetes. N Engl J Med. 2001 Sep;345(12): 870-8.

18 Kshirsagar AV, Joy MS, Hogan SL, Falk RJ, Colindres RE. Effect of ACE inhibitors in diabetic and nondiabetic chronic renal disease: a systematic overview of randomized placebocontrolled trials. Am J Kidney Dis. 2000 Apr; 35(4):695-707.
19 Ruggenenti P, Perna A, Remuzzi G; GISEN Group Investigators. Retarding progression of chronic renal disease: the neglected issue of residual proteinuria. Kidney Int. 2003 Jun; 63(6):2254-61.

20 Praga M, Morales E. Renal damage associated with proteinuria. Kidney Int Suppl. 2002 Dec; (82):S42-6.

21 Law MR, Morris JK, Wald NJ. Use of blood pressure lowering drugs in the prevention of cardiovascular disease: meta-analysis of 147 randomised trials in the context of expectations from prospective epidemiological studies. BMJ. 2009 May;338(May 19): b1665.

22 Engberink RHGO, Frenkel WJ, Van Den Bogaard B, Brewster LM, Vogt L, Van Den Born BJH. Effects of thiazide-type and thiazide-like diuretics on cardiovascular events and mortality: systematic review and metaanalysis. Hypertension. 2015; 65(5):103340.

23 Rose BD. Diuretics. Kidney Int. 1991 Feb 39(2):336-52.

24 Terada Y, Knepper MA. Thiazide-sensitive $\mathrm{NaCl}$ absorption in rat cortical collecting duct. Am J Physiol. 1990 Sep;259(3):F519-28.

25 Krikken JA, Lely AT, Bakker SJL, Navis G. The effect of a shift in sodium intake on renal hemodynamics is determined by body mass index in healthy young men. Kidney Int. 2007;71(3):260-5.

26 Weir MR, Dengel DR, Behrens MT, Goldberg AP. Salt-induced increases in systolic blood pressure affect renal hemodynamics and proteinuria. Hypertension. 1995 Jun;25(6):133944.

27 Bigazzi R, Bianchi S, Baldari D, Sgherri G, Baldari G, Campese VM. Microalbuminuria in salt-sensitive patients. A marker for renal and cardiovascular risk factors. Hypertension. 1994 Feb;23(2):195-9.

28 Jerums G, Allen TJ, Tsalamandris C, Cooper ME. Angiotensin converting enzyme inhibition and calcium channel blockade in incipient diabetic nephropathy. The Melbourne Diabetic Nephropathy Study Group. Kidney Int. 1992 Apr;41(4):904-11. 
29 Gansevoort RT, de Zeeuw D, de Jong PE. Long-term benefits of the antiproteinuric effect of angiotensin-converting enzyme inhibition in nondiabetic renal disease. Am J Kidney Dis. 1993 Jul;22(1):202-6.

30 Heerspink HJL, Holtkamp FA, Parving HH, Navis GJ, Lewis JB, Ritz E, et al. Moderation of dietary sodium potentiates the renal and cardiovascular protective effects of angiotensin receptor blockers. Kidney Int. 2012;82(3): $330-7$.

31 Vegter S, Perna A, Postma MJ, Navis G, Remuzzi G, Ruggenenti P. Sodium intake, ACE inhibition, and progression to ESRD. J Am Soc Nephrol. 2012;23(1):165-73.

32 Buter H, Hemmelder MH, Navis G, De Jong $\mathrm{PE}$, De Zeeuw D. The blunting of the antiproteinuric efficacy of ACE inhibition by high sodium intake can be restored by hydrochlorothiazide. Nephrol Dial Transplant. 1998; 13(7):1682-5

33 Nielsen S, Dollerup J, Nielsen B, Mogensen CE. Combination of enalapril and low-dose thiazide reduces normoalbuminuria in essential hypertension. J Hypertens. 1998;16(10): 1539-44.

34 Uzu T, Harada T, Namba T, Yamamoto R, Takahara K, Yamauchi A, et al. Thiazide diuretics enhance nocturnal blood pressure fall and reduce proteinuria in immunoglobulin $\mathrm{A}$ nephropathy treated with angiotensin II modulators. J Hypertens. 2005;23(4):861-5.

35 Vogt L, Waanders F, Boomsma F, De Zeeuw D, Navis G. Effects of dietary sodium and hydrochlorothiazide on the antiproteinuric efficacy of losartan. J Am Soc Nephrol. 2008; 19(5):999-1007.

36 Zhou MS, Schulman IH, Jaimes EA, Raij L. Thiazide diuretics, endothelial function, and vascular oxidative stress. J Hypertens. 2008; 26(3):494-500.

37 Kwakernaak AJ, Krikken JA, Binnenmars SH, Visser FW, Hemmelder MH, Woittiez AJ, et al. Effects of sodium restriction and hydrochlorothiazide on RAAS blockade efficacy in diabetic nephropathy: a randomised clinical trial. Lancet Diabetes Endocrinol. 2014;2(5): 385-95.

38 Fujisaki K, Tsuruya K, Nakano T, Taniguchi M, Higashi H, Katafuchi R, et al. Impact of combined losartan/hydrochlorothiazide on proteinuria in patients with chronic kidney disease and hypertension. Hypertens Res. 2014;37(11):993-8.

39 Hoshino T, Ookawara S, Miyazawa H, Ito K, Ueda Y, Kaku Y, et al. Renoprotective effects of thiazides combined with loop diuretics in patients with type 2 diabetic kidney disease. Clin Exp Nephrol. 2015;19(2):247-53.

40 Morales E, Caro J, Gutierrez E, Sevillano A, Auñón P, Fernandez C, et al. Diverse diuretics regimens differentially enhance the antialbuminuric effect of renin-angiotensin blockers in patients with chronic kidney disease. Kidney Int. 2015;88(6):1434-41.

41 Agarwal R, Sinha AD, Pappas MK, Ammous F. Chlorthalidone for poorly controlled hy- pertension in chronic kidney disease: an interventional pilot study. Am J Nephrol. 2014; 39(2):171-82.

42 Moes AD, Hesselink DA, van den Meiracker $\mathrm{AH}$, Zietse R, Hoorn EJ. Chlorthalidone versus amlodipine for hypertension in kidney transplant recipients treated with tacrolimus: a randomized crossover trial. Am J Kidney Dis. 2017;69(6):796-804.

43 Huen SC, Goldfarb DS. Adverse metabolic side effects of thiazides: implications for patients with calcium nephrolithiasis. J Urol. 2007;177(4):1238-43.

44 Letellier T, Leborgne F, Kerleau C, Gaultier A, Dantal J, Ville S. Association between use of hydrochlorothiazide and risk of keratinocyte cancers in kidney transplant recipients. Clin J Am Soc Nephrol. 2020 Dec;15(12):1804-13.

45 Marre M, Puig JG, Kokot F, Fernandez M, Jermendy G, Opie L, et al. Equivalence of indapamide SR and enalapril on microalbuminuria reduction in hypertensive patients with type 2 diabetes: the NESTOR study. J Hypertens. 2004;22(8):1613-22

46 Molyneaux LM, Willey KA, Yue DK. Indapamide is as effective as captopril in the control of microalbuminuria in diabetes. J Cardiovasc Pharmacol. 1996 Mar;27(3):424-7.

47 Gambardella S, Frontoni S, Felici MG, Spallone V, Gargiulo P, Morano S, et al. Efficacy of antihypertensive treatment with indapamide in patients with noninsulin-dependent diabetes and persistent microalbuminuria. Am J Cardiol. 1990 May;65(17):46H-50.

48 Gambardella S, Frontoni S, Lala A, Felici MG, Spallone V, Scoppola A, et al. Regression of microalbuminuria in type II diabetic, hypertensive patients after long-term indapamide treatment. Am Heart J. 1991 Oct;122(4): $1232-8$.

49 Esnault VLM, Ekhlas A, Delcroix C, Moutel MG, Nguyen JM. Diuretic and enhanced sodium restriction results in improved antiproteinuric response to RAS blocking agents. J Am Soc Nephrol. 2005;16(2):474-81.

50 Esnault VLM, Ekhlas A, Nguyen JM, Moranne O. Diuretic uptitration with half dose combined ACEI + ARB better decreases proteinuria than combined ACEI + ARB uptitration. Nephrol Dial Transplant. 2010;25(7): 2218-24.

51 Arias SCA, Souza RA, Malheiros DMAC, Fanelli C, Fujihara CK, Zatz R. An association of losartan-hydrochlorothiazide, but not losartan-furosemide, completely arrests progressive injury in the remnant kidney. Am J Physiol Renal Physiol. 2016 Jan;310(2):F13543.

52 Aldigier JC, Kanjanbuch T, Ma LJ, Brown NJ, Fogo AB. Regression of existing glomerulosclerosis by inhibition of aldosterone. J Am Soc Nephrol. 2005;16(11):3306-14.

53 Rocha R, Chander PN, Khanna K, Zuckerman A, Stier CT. Mineralocorticoid blockade reduces vascular injury in stroke-prone hypertensive rats. Hypertension. 1998;31(1): 451-8.
54 Blasi ER, Rocha R, Rudolph AE, Blomme EAG, Polly ML, McMahon EG. Aldosterone/ salt induces renal inflammation and fibrosis in hypertensive rats. Kidney Int. 2003 May; 63(5):1791-800.

55 Bianchi S, Bigazzi R, Campese VM. Longterm effects of spironolactone on proteinuria and kidney function in patients with chronic kidney disease. Kidney Int. 2006 Dec;70(12): 2116-23.

56 Chrysostomou A, Pedagogos E, MacGregor L, Becker GJ. Double-blind, placebo-controlled study on the effect of the aldosterone receptor antagonist spironolactone in patients who have persistent proteinuria and are on long-term angiotensin-converting enzyme inhibitor therapy, with or without an angiotensin II receptor blocker. Clin J Am Soc Nephrol. 2006;1(2):256-62.

57 Rossing K, Schjoedt KJ, Smidt UM, Boomsma F, Parving HH. Beneficial effects of adding spironolactone to recommended antihypertensive treatment in diabetic nephropathy: a randomized, double-masked, cross-over study. Diabetes Care. 2005;28(9): 2106-12.

58 Schjoedt KJ, Rossing K, Juhl TR, Boomsma F, Rossing P, Tarnow L, et al. Beneficial impact of spironolactone in diabetic nephropathy. Kidney Int. 2005 Dec;68(6): 2829-36.

59 Bakris GL, Agarwal R, Chan JC, Cooper ME, Gansevoort RT, Haller H, et al. Effect of finerenone on albuminuria in patients with diabetic nephropathy. JAMA. 2015 Sep;314(9): 884-94.

60 Bakris GL, Agarwal R, Anker SD, Pitt B, Ruilope LM, Rossing P, et al. Effect of finerenone on chronic kidney disease outcomes in type 2 diabetes. N Engl J Med. 2020 Oct; 383(23):2219-222.

61 Staessen J, Lijnen P, Fagard R, Verschueren $\mathrm{LJ}$, Amery A. Rise in plasma concentration of aldosterone during long-term angiotensin II suppression. J Endocrinol. 1981;91(3):45765.

62 Bomback AS, Kshirsagar AV, Amamoo MA Klemmer PJ. Change in proteinuria after adding aldosterone blockers to ACE inhibitors or angiotensin receptor blockers in CKD: a systematic review. Am J Kidney Dis. 2008 Feb; 51(2):199-211.

63 Bolignano D, Palmer SC, Navaneethan SD, Strippoli GFM. Aldosterone antagonists for preventing the progression of chronic kidney disease. Cochrane Database Syst Rev. 2014 Apr;2014(4):CD007004.

64 Maron BA, Leopold JA. Aldosterone receptor antagonists: effective but often forgotten. Circulation. $2010 \mathrm{Feb} ; 121(7): 934-9$.

65 Alexandrou ME, Papagianni A, Tsapas A, Loutradis C, Boutou A, Piperidou A, et al. Effects of mineralocorticoid receptor antagonists in proteinuric kidney disease: a systematic review and meta-Analysis of randomized controlled trials. J Hypertens. 2019 Dec; 37(12):2307-24. 
66 Morales E, Millet VG, Rojas-Rivera J, Huerta A, Gutiérrez E, Gutiérrez-Solís E, et al. Renoprotective effects of mineralocorticoid receptor blockers in patients with proteinuric kidney diseases. Nephrol Dial Transplant. 2013;28(2):405-12.

67 Minakuchi $\mathrm{H}$, Wakino S, Urai H, Kurokochi A, Hasegawa K, Kanda T, et al. The effect of aldosterone and aldosterone blockade on the progression of chronic kidney disease: a randomized placebo-controlled clinical trial. Sci Rep. 2020;10(1):16626.

68 Esteghamati A, Noshad S, Jarrah S, Mousavizadeh M, Khoee SH, Nakhjavani M. Longterm effects of addition of mineralocorticoid receptor antagonist to angiotensin II receptor blocker in patients with diabetic nephropathy: a randomized clinical trial. Nephrol Dial Transplant. 2013;28(11):2823-33.

69 Epstein M, Williams GH, Weinberger M, Lewin A, Krause S, Mukherjee R, et al. Selective aldosterone blockade with eplerenone reduces albuminuria in patients with type 2 diabetes. Clin J Am Soc Nephrol. 2006;1(5):940-51.

70 Nielsen SE, Persson F, Frandsen E, Sugaya T, Hess G, Zdunek D, et al. Spironolactone diminishes urinary albumin excretion in patients with type 1 diabetes and microalbuminuria: a randomized placebo-controlled crossover study. Diabet Med. 2012 Aug;29(8):e184.

71 Epstein M, Buckalew V, Martinez F, Altamirano J, Roniker B, Kleiman J, et al. OR-54: antiproteinuric efficacy of eplerenone, enalapril, and eplerenone/enalapril combination therapy in diabetic hypertensives with microalbuminuria. Am J Hypertens. 2002;15(4):24A.

72 Boesby L, Elung-Jensen T, Klausen TW, Strandgaard S, Kamper A-L. Moderate antiproteinuric effect of add-on aldosterone blockade with eplerenone in non-diabetic chronic kidney disease. A randomized crossover study. PLoS One. 2011;6(11):e26904.

73 Agarwal R, Kolkhof P, Bakris G, Bauersachs J, Haller H, Wada TZF. Steroidal and non-steroidal mineralocorticoid receptor antagonists in cardiorenal medicine. Eur Heart J. 2021; 42(2):152-61.

74 Tsuboi N, Kawamura T, Okonogi H, Ishii T, Hosoya $\mathrm{T}$. The long-term antiproteinuric effect of eplerenone, a selective aldosterone blocker, in patients with non-diabetic chronic kidney disease. J Renin Angiotensin Aldosterone Syst. 2012 Mar;13(1):113-7.

75 Ando K, Ohtsu H, Uchida S, Kaname S, Arakawa Y, Fujita T. Anti-albuminuric effect of the aldosterone blocker eplerenone in nondiabetic hypertensive patients with albuminuria: a double-blind, randomised, placebocontrolled trial. Lancet Diabetes Endocrinol. 2014;2(12):944-53.

76 Chung EY, Ruospo M, Natale P, Bolignano D, Navaneethan SD, Palmer SC, et al. Aldosterone antagonists in addition to renin angiotensin system antagonists for preventing the progression of chronic kidney disease. Cochrane Database Syst Rev. 2020 Oct;10:CD007004.

77 Khan MS, Khan MS, Moustafa A, Anderson AS, Mehta R, Khan SS. Efficacy and safety of mineralocorticoid receptor antagonists in patients with heart failure and chronic kidney disease. Am J Cardiol. 2020;125(4):643-50.

78 Charytan DM, Himmelfarb J, Ikizler TA, Raj DS, Hsu JY, Landis JR, et al. Safety and cardiovascular efficacy of spironolactone in dialysisdependent ESRD (SPin-D): a randomized, placebo-controlled, multiple dosage trial. Kidney Int. 2019 Apr;95(4):973-82.

79 Rico-Mesa JS, White A, Ahmadian-Tehrani A, Anderson AS. Mineralocorticoid receptor antagonists: a comprehensive review of finerenone. Curr Cardiol Rep. 2020;22(11):140-11.

80 Dutzmann J, Musmann RJ, Haertlé M, Daniel JM, Sonnenschein K, Schäfer A, et al. The novel mineralocorticoid receptor antagonist finerenone attenuates neointima formation after vascular injury. PLoS One. 2017 Sep; 12(9): 0184888.

81 Siddiqui M, Calhoun DA. Refractory versus resistant hypertension. Curr Opin Nephrol Hypertens. 2017;26(1):14-9.

82 Williams B, Macdonald TM, Morant S, Webb DJ, Sever P, McInnes G, et al. Spironolactone versus placebo, bisoprolol, and doxazosin to determine the optimal treatment for drug-resistant hypertension (PATHWAY-2): a randomised, double-blind, crossover trial. Lancet. 2015;386(10008):2059-68.

83 Kolkhof P, Bärfacker L. Mineralocorticoid receptor antagonists: 60 years of research and development. J Endocrinol. 2017;234(1):T125-40.

84 Zhang B, Xie S, Shi W, Yang Y. Amiloride offtarget effect inhibits podocyte urokinase receptor expression and reduces proteinuria. Nephrol Dial Transplant. 2012;27(5):1746-55.

$85 \mathrm{Xu} \mathrm{LB}$, Chi N, Shi W. Amiloride, a urokinasetype plasminogen activator receptor (uTPA) inhibitor, reduces proteinurea in podocytes. Genet Mol Res. 2015;14(3):9518-29.

86 Saleem MA. What is the role of soluble urokinase-type plasminogen activator in renal disease? Nephron. 2018;139(4):334-41.

87 Trimarchi H, Forrester M, Lombi F, Pomeranz V, Raña MS, Karl A, et al. Amiloride as an alternate adjuvant antiproteinuric agent in fabry disease: the potential roles of plasmin and UPAR. Case Rep Nephrol. 2014;2014:854521-6.

88 Svenningsen P, Bistrup C, Friis UG, Bertog M, Haerteis S, Krueger B, et al. Plasmin in nephrotic urine activates the epithelial sodium channel. J Am Soc Nephrol. 2009;20(2):299310.

89 Unruh ML, Pankratz VS, Demko JE, Ray EC, Hughey RP, Kleyman TR. Trial of amiloride in type 2 diabetes with proteinuria. Kidney Int Rep. 2017;2(5):893-904.

90 Kassamali R, Sica DA. Acetazolamide: a forgotten diuretic agent. Cardiol Rev. 2011; 19(6):276-8.

91 León Jiménez D, Gómez Huelgas R, Fernández Romero AJ, López Chozas JM, Pérez de Isla L, Miramontes González JP. Diuretic treatment of the patient with diabetes and heart failure. Role of SGLT2 inhibitors and similarities with carbonic anhydrase inhibitors. Rev Clin Esp. 2019;219(4):208-17.
92 Bradwell AR, Wright AD, Winterborn M, Imray C. Acetazolamide and high altitude diseases. Int J Sports Med. 1992;13(Suppl 1):S63-4.

93 Bradwell AR, Delamere JP. The effect of acetazolamide on the proteinuria of altitude. Aviat Space Environ Med. 1982 Jan;53(1): 40-3.

94 Zingerman B, Herman-Edelstein M, Erman A, Itach SBS, Ori Y, Rozen-Zvi B, et al. Effect of acetazolamide on obesity-induced glomerular hyperfiltration: a randomized controlled trial. PLoS One. 2015;10(9): e0137163-16.

95 Wilcox CS. Antihypertensive and renal mechanisms of SGLT2 (sodium-glucose linked transporter 2) inhibitors. Hypertension. 2020;75(4):894-901.

96 van Bommel EJM, Muskiet MHA, van Baar MJB, Tonneijck L, Smits MM, Emanuel AL, et al. The renal hemodynamic effects of the SGLT2 inhibitor dapagliflozin are caused by post-glomerular vasodilatation rather than pre-glomerular vasoconstriction in metformin-treated patients with type 2 diabetes in the randomized, double-blind RED trial. Kidney Int. 2020 Jan;97(1):202-12.

97 Skøtt P, Hommel E, Bruun NE, Arnold-Larsen S, Parving HH. Effects of acetazolamide on kidney function in type 1 (insulin-dependent) diabetic patients with diabetic nephropathy. Diabetologia. 1988 Nov;31(11):806-10.

98 Oliva RV, Bakris GL. Blood pressure effects of sodium-glucose co-transport 2 (SGLT2) inhibitors. J Am Soc Hypertens. 2014;8(5): $330-9$.

99 Eickhoff MK, Dekkers CCJ, Kramers BJ, Laverman GD, Frimodt-Møller M, Jørgensen NR, et al. Effects of dapagliflozin on volume status when added to Renin-Angiotensin system inhibitors. J Clin Med. 2019 May;8(6):779.

100 Wilcox CS, Shen W, Boulton DW, Leslie BR Griffen SC. Interaction between the sodiumglucose-linked transporter 2 inhibitor dapagliflozin and the loop diuretic bumetanide in normal human subjects. J Am Heart Assoc. 2018 Feb;7(4):e007046.

101 Solini A, Giannini L, Seghieri M, Vitolo E, Taddei S, Ghiadoni L, et al. Dapagliflozin acutely improves endothelial dysfunction, reduces aortic stiffness and renal resistive index in type 2 diabetic patients: a pilot study. Cardiovasc Diabetol. 2017 Oct;16(1):138.

102 Lambers Heerspink HJ, De Zeeuw D, Wie L, Leslie B, List J. Dapagliflozin a glucose-regulating drug with diuretic properties in subjects with type 2 diabetes. Diabetes Obes Metab. 2013;15(9):853-62.

103 Nangaku M. More reasons to use SGLT2 inhibitors: EMPEROR-reduced and DAPACKD. Kidney Int. 2020;98(6):1387-9.

104 Tanaka S, Sugiura Y, Saito H, Sugahara M, Higashijima Y, Yamaguchi J, et al. Sodiumglucose cotransporter 2 inhibition normalizes glucose metabolism and suppresses oxidative stress in the kidneys of diabetic mice. Kidney Int. 2018 Nov;94(5):912-25. 
105 Hesp AC, Schaub JA, Prasad PV, Vallon V, Laverman GD, Bjornstad P, et al. The role of renal hypoxia in the pathogenesis of diabetic kidney disease: a promising target for newer renoprotective agents including SGLT2 inhibitors? Kidney Int. 2020 Sep;98(3):57989.

106 Vergara A, Jacobs-Cachá C, Soler MJ. Sodium-glucose cotransporter inhibitors: beyond glycaemic control. Clin Kidney J. 2019; 12(3):322-5.

107 Zelniker TA, Wiviott SD, Raz I, Im K, Goodrich EL, Bonaca MP, et al. SGLT2 inhibitors for primary and secondary prevention of cardiovascular and renal outcomes in type 2 diabetes: a systematic review and meta-analysis of cardiovascular outcome trials. Lancet. 2019 Jan;393(10166):31-9.

108 Wanner C, Inzucchi SE, Lachin JM, Fitchett D, von Eynatten M, Mattheus M, et al. Empagliflozin and progression of kidney disease in type 2 diabetes. N Engl J Med. 2016; 375(4):323-34.

109 Packer M, Anker SD, Butler J, Filippatos G, Pocock SJ, Carson P, et al. Cardiovascular and renal outcomes with empagliflozin in heart failure. N Engl J Med. 2020 Aug 8; 383(15):1413-24.

110 Heerspink HJL, Stefánsson BV, Correa-Rotter R, Chertow GM, Greene T, Hou F-F, et al. Dapagliflozin in patients with chronic kidney disease. N Engl J Med. 2020;383: 1436-46.

111 Neal B, Perkovic V, Mahaffey KW, de Zeeuw D, Fulcher G, Erondu N, et al. Canagliflozin and cardiovascular and renal events in type 2 diabetes. N Engl J Med. 2017;377(7):64457.

112 Perkovic V, Jardine MJ, Neal B, Bompoint S, Heerspink HJL, Charytan DM, et al. Canagliflozin and renal outcomes in type 2 diabetes and nephropathy. N Engl J Med. 2019; 380(24):2295-306.

113 Bakris G, Oshima M, Mahaffey KW, Agarwal R, Cannon CP, Capuano G, et al. Effects of canagliflozin in patients with baseline eGFR $<30 \mathrm{~mL} / \mathrm{min}$ per $1.73 \mathrm{~m} 2$. Clin J Am Soc Nephrol. 2020 Dec 7;15(12):1705-14.

114 Wiviott SD, Raz I, Bonaca MP, Mosenzon O, Kato ET, Cahn A, et al. Dapagliflozin and cardiovascular outcomes in type 2 diabetes. N Engl J Med. 2019;380(4):347-57.
115 Idzerda NMA, Stefansson BV, Pena MJ, Sjostrom DC, Wheeler DC, Heerspink HJL. Prediction of the effect of dapagliflozin on kidney and heart failure outcomes based on short-term changes in multiple risk markers. Nephrol Dial Transplant. 2020 Sep;35(9): 1570-6.

116 Oshima M, Neuen BL, Li JW, Perkovic V, Charytan DM, de Zeeuw D, et al. Early change in albuminuria with canagliflozin predicts kidney and cardiovascular outcomes: a post hoc analysis from the credence trial. J Am Soc Nephrol. 2020;31(12):292536.

117 Cherney DZI, Dekkers CCJ, Barbour SJ, Cattran D, Abdul Gafor AH, Greasley PJ, et al. Effects of the SGLT2 inhibitor dapagliflozin on proteinuria in non-diabetic patients with chronic kidney disease (DIAMOND): a randomised, double-blind, crossover trial. Lancet Diabetes Endocrinol. 2020 Jul;8(7):582-93.

118 Heerspink HJL, Kröpelin TF, Hoekman J, de Zeeuw D; Reducing Albuminuria as Surrogate Endpoint (REASSURE) Consortium. Drug-induced reduction in albuminuria is associated with subsequent renoprotection: a meta-analysis. J Am Soc Nephrol. 2015 Aug;26(8):2055-64.

119 Coresh J, Heerspink HJL, Sang Y, Matsushita K, Arnlov J, Astor BC, et al. Change in albuminuria and subsequent risk of endstage kidney disease: an individual participant-level consortium meta-analysis of observational studies. Lancet Diabetes Endocrinol. 2019;7(2):115-27.

120 Inker LA, Mondal H, Greene T, Masaschi T, Locatelli F, Schena FP, et al. Early change in urine protein as a surrogate end point in studies of IgA nephropathy: an individualpatient meta-analysis. Am J Kidney Dis. 2016 Sep;68(3):392-401.

121 Abbate M, Zoja C, Remuzzi G. How does proteinuria cause progressive renal damage? J Am Soc Nephrol. 2006 Nov;17(11):297484.

122 Remuzzi G, Bertani T. Is glomerulosclerosis a consequence of altered glomerular permeability to macromolecules? Kidney Int. 1990; 38(3):384-94.
123 Wang Y, Chen J, Chen L, Tay YC, Rangan GK, Harris DC. Induction of monocyte chemoattractant protein-1 in proximal tubule cells by urinary protein. J Am Soc Nephrol. 1997;8(10):1537-45.

124 Zoja C, Donadelli R, Colleoni S, Figliuzzi M, Bonazzola S, Morigi M, et al. Protein overload stimulates RANTES production by proximal tubular cells depending on NFkappa B activation. Kidney Int. 1998;53: 1608-15.

125 Zoja C, Morigi M, Figliuzzi M, Bruzzi I, Oldroyd S, Benigni A, et al. Proximal tubular cell synthesis and secretion of endothelin-1 on challenge with albumin and other proteins. Am J Kidney Dis. 1995;26(6):934-41.

126 Donadelli R, Abbate M, Zanchi C, Corna D, Tomasoni S, Benigni A, et al. Protein traffic activates NF-kB gene signaling and promotes MCP-1-dependent interstitial inflammation. Am J Kidney Dis. 2000;36(6): 1226-41.

127 Abbate M, Zoja C, Rottoli D, Corna D, Tomasoni S, Remuzzi G. Proximal tubular cells promote fibrogenesis by TGF-beta1-mediated induction of peritubular myofibroblasts. Kidney Int. 2002;61(6):2066-77.

128 Tang S, Sheerin NS, Zhou W, Brown Z, Sacks SH. Apical proteins stimulate complement synthesis by cultured human proximal tubular epithelial cells. J Am Soc Nephrol. 1999;10(1):69-76.

129 Waijer SW, Xie D, Inzucchi SE, Zinman B, Koitka-Weber A, Mattheus M, et al. Shortterm changes in albuminuria and risk of cardiovascular and renal outcomes in type 2 diabetes mellitus: a post hoc analysis of the EMPA-REG outcome trial. J Am Heart Assoc. 2020 Sep;9(18):e016976.

130 Thompson A, Smith K, Lawrence J. Change in estimated GFR and albuminuria as end points in clinical trials: a viewpoint from the FDA. Am J Kidney Dis. 2020;75(1):4-5.

131 Holtkamp F, Gudmundsdottir H, Maciulaitis R, Benda N, Thomson A, Vetter T. Change in albuminuria and estimated GFR as end points for clinical trials in early stages of CKD: a perspective from European regulators. Am J Kidney Dis. 2020;75(1):6- 